\title{
O Processo Civil na Perspectiva dos Direitos Fundamentais
}

\author{
C. A. Alvaro de Oliveira
}

Professor Titular da Faculdade de Direito da UFR GS

1.A dimensão conquistada pelo direito constitucional em relação a todos tamos do direito e na própria hermenêutica jurídica (v.g., "a interpretação conforme à Constituição") mostra-se particularmente intensa no que diz respeito ao processo.

Já no século XVII apreendera-se que o exercicio da jurisdição constitui faceta importante do exercício do poder. Daí a apropriação do ordo iudiciarius pelo Príncipe, de que é exemplo emblemático o chamado Code Louis".

Atualmente, pode-se até dizer do ponto de vista interno que a conformação e a organização do processo e do procedimento nada mais representam do que o equacionamento de conflitos entre princípios constitucionais em tensão, de conformidade com os fatores

\footnotetext{
'Ordenance Civile du mois d'avril 1667, denominada Code Louis. Nicola Picardi, il Giudice e la Legge nel Code Louis, in Rivista di Diritto Processuale, L(1995):33-48, esp. p. 35.36, ressalta com razão que, com a instituiçāo do Code Louis, o reijuiz do constitucionalismo medieval passava a ser substituído pelo reilegislador; o direito tornava-se reduzido à lei e a lei à vontade do soberano. Em consequuência, a iurisdictio terminava por perder o caxáter originário de poder soberano tout court, e, com sua inagem do julgar, era destinada a cobrir uma esfera de poder diferente do poder de legislar, tornando-se o último já a marca distintiva da soberania.
} 
culturais, sociais, políticos, econômicos e as estratégias de poder em deteminado espaço social e temporal ${ }^{2}$. Basta pensar na permanente disputa entre os princípios da efetividade e da segurança jurídica.

Significativamente, no final do século XIX era presente entre nós a compreensão da influência da norma constitucional no processo, especialmente como meio para a efe tividade e segurança dos direitos. Para João Mendes Júnior, o processo, na medida em que garante os direitos individuais, deita suas taizes na lei constitucional. Cada ato do processo "deve ser considerado meio, não só para chegar ao firn próximo, que é o julgamento, como ao fim remoto, que é a segurança constitucional dos direitos." Suprimit, assim, formalidades processuais pode constituir "ofensa da garantia constitucional da segurança dos direitos e da execução das leis federais".

Em obra diversa, adiantando lições de outras épocas, o grande mestre como que intuiu a íntima conexidade entre o direito processual e constitucional, ao consignar que "As leis do processo são o complemento necessário das leis constitucionais; as formalidades do processo as atualidades das gatantias constitucionais. Se o modo e a forma da tealização dessas garantias fossem deixados ao critério das partes ou à discrição dos juizes, a justiça, marchando sern guia, mesmo sob o mais prudente dos arbítrios, seria uma ocasião constante de desconfiança e surpresas" ". Antecipa-se desse modo, com grande descortino, futuras elaboraçóes da doutrina européia do século XX.

Realmente, sc o processo, na sua condição de autêntica ferramenta de natureza pública indispensável para a realização da justiça e da pacificação social, não pode ser compteendido como mera técnica mas, sim, como instrumento de realização de valores e especialmente de valores constitucionais ${ }^{5}$, impõe-se considerá-lo como direito constitucional aplicado .

\footnotetext{
${ }^{2}$ Ainda está por ser realizada, do ponto de vista sociológico, uma investigação que mostre como, raa atual sociedade informática e globalizada, a difusão de modelos culturais de forma instantântea pela televisão via satélite, pela internet, pelo rádio, fiimes, ensaios, artigos, revistas, livros etc. poderá vir a aproximar mundos diferentes e até a homogeneizá-los e quando isso se tornará possivel.

${ }^{3}$ João Mendes Júnjor, A Nova Fase da Doutrina e das Leis do Processo Brasileiro, in Revista da Faculdade de Direito de São Paulo, 1899, p. 120, apud José Frederico Marques, Ensaio sobre a Jurisdição Voluntária, São Paulo, Sarajua, 1959, p. 23.

${ }^{4}$ Joăo Mendes Júnior, O Processo Criminal Btasileiro, 2a. ed., vol. I, p. 8, apud José Ftedexico Marques, Ensaio sobre a Juxisdição Voluntária, cit., p. 21-22.

${ }^{5}$ Cf. C. A Avaro de Olveira, Do Formalismo no Processo Civil, Sảo Paulo, Saraiva, 1997, p. 73.76 e 8384. Sobre o fenômeno cultural e sua influência no processo, o ensaio pioneiro entre nós de Galeno Lacerda, Processo e Cultura, Revista de Direito Processual Civil, 3(1962):74-86, passim.

"Assim, Hans Friedhelm Gaul, Zur Frage nach dem Zweck des Zivilprocezesses, Archiv für die Civilistische Práxis, 168(1968):27-62, esp. p. 32. Idéia semelhante em Rudolf Pollak, Sistem des Osterreichischen Zivilprozessrechtes., 2a. ed., Wien, Manz, 1932, p. III, para quetn o direito processual civil constitui, em muitos aspectos, una das mais importantes partes do direito constitucional.
} 
Nos dias atuais, cresce em significado a importância dessa concepção, se atentarmos para a intima conexidade entre a jurisdição e o instrumento processual na aplicação e proteção dos direitos e garantias assegurados na Constituição. Aqui não se trata mais, bem entendido, de apenas conformar o processo às normas constitucionais, mas de empregá-las no próprio exercício da função jurisdicional, com reflexo direto no seu conteúdo, naquilo que é decidido pelo órgão judicial e na maneira como o processo é por ele conduzido. Este último aspecto, ressalte-se, de modo geral é descurado pela doutrina. Tudo isso é potencializado por dois fenômenos fundamentais de nossa época: o afastamento do modelo lógico próprio do positivismo jurídico, com a adoção de lógicas mais aderentes à realidade jurídica, como a tópica-retórica, e a conseqüente intensificação dos princípios, sejam eles decorrentes de texto legal ou constitucional ou não.

2. No contexto antes delineado ressalta a importancia dos direitos fundamentaís ${ }^{\text {, }}$, visto que criam os pressupostos básicos para uma vida na liberdade e na dignidade humana". Cuidase, portanto, dos direitos inerentes à própria noção dos direitos básicos da pessoa, que constituem a base jurídica da vida humana no seu nível atual de dignidade. Claro que não se trata apenas dos direitos estatuídos pelo legislador constituinte, mas também dos direitos resultantes da concepção de Constituição dominante, da idéía de Direito, do sentimento jurídico coletivo".

A importância dos direitos fundamentais decorre ainda de outra circunstância. Além de serem tautologicamente fundamentais, a evolução da humanidade passou a exigir uma nova concepção de efetividade dos direitos fundamentais. Do sentido puramente abstrato e metafísico da Declaração dos Direitos do Komenn de 1789, a partir da Declaração Universal dos Direitos do Homem de 1948, evoluiu-se para uma nova universalidade dos direitos fundamentais de modo a colocá-los num grau mais alto de juridicidade, conctetude, positividade e eficácia ${ }^{10}$.

${ }^{7}$ É grande a incerteza teminológica a respeito. Fala-se em direitos naturais, direitos humanos, direitos do homem, direitos individuais, direitos públicos subjetivos, liberdades fundamentais, liberúades públicas, direitos fundamentais do homem (José Afonso da Silva, Cuxso de Direito Constitucional, p. 157). Dou preferência à expressão "direitos fundamentais" não só porque já incorporada à tradição, como também porque expressa razoavelmente a concepção adotada no texto.

${ }^{\circledR}$ Assim, Konrad Hesse, apud Paulo Bonavides, Curso de Direito Constitucional, 7a. ed., São Paulo, Malheiros, 1997, p. 514. Ainda segundo Hesse, os direitos fundamentais, mais restritamente, são aqueles qualificados como tais pelo direito vigente. Consoante José Afonso da Silva, Curso, cit, p. 159, os direitos fundamentais estabelecem os princípios consubstanciadores da concepção do mundo e da ideologia política de cada ordenamento juridico, designando as prerrogativas e instituiçoes com que o direito positivo concretiza as garantias de uma convivência digna, livre e igualitária de todas as pessoas.

"Cf. Jorge Miranda, Manual de Direito Constitucional, tomo IV, Direitos Fundamentais, Coimbra, Coimbra ed., 1988, p. 8.10.

${ }^{10} \mathrm{~A}$ busca da efetividade dos direitos fundamentais, bem assinala Serge Guinchard, Droit processuel Droit commum du procès, em colaboração com Monique Bandrac, Xavier Lagarde e Mélina Douchy, Paris, Dalloz, 2001, p. 53-54, é o fenômeno mais marcante do final do século XX. Menciona ele o célebre aresto Arey vs. Irianda, de 7.10.1979, em que a Corte Européia dos Direitos do Homem manifestou sua clara preocupação com a exigência "de proteger não mais de forma teórica ou ilusória, mas de forma concreta e efetiva", os direitos fundamentais. 
Essa nova universalidade busca subjetivar de forma concreta e positiva os direitos de tríplice geração na titulatidade de um indivíduo, que, antes de ser o homem deste ou daquele país, de uma sociedade desenvolvida ou subdesenvolvida, é, pela sua condição de pessoa, um ente qualificado por sua pertinência ao gêneto humano, objeto daquela universalidade $"$.

Relembre-se que os direitos de primeira geração são os direitos da liberdade, a saber, os direitos civis e políticos assegurados no plano constitucional; os da segunda geração dizem respeito aos direitos sociais, culturais e econômicos, bem como aos direitos coletivos. A terceira geração compreende os direitos da fraternidade, ultrapassando os limites dos direitos individuais ou mesmo coletivos: o direito ao desenvolvimento, o direito à paz, o direito ao meio ambiente, o direito de propriedade sobre o patrimônio comum da humaridade e o direito de comunicação ${ }^{12}$.

3. No sistema jurídico brasileiro, essas ponderações ostentam enorme alcance prático, porque a Constituição de 1988 positivou de forma expressa os direitos fundamentais de primeira, segunda e terceira geração.

Além disso, o $\int 1^{\circ}$ do art. $5^{\circ}$ da Constituição brasileira estatui de modo expresso que "As normas definidoras dos direitos e garantias fundamentais têm aplicação imediata".

Esta última disposição constitucional reveste-se de grande significado. Por um lado, principalmente em matéria processual, os preceitos consagradores dos direitos fundamentais rão dependem da edição de leis concretizadoras. Por outro, na Constituição brasileira, os direitos fundamentais de caráter processual ou informadores do processo não tiveram sua eficácia plena condicionada à regulação por lei infraconstitucional.

Demais disso, já não se discure mais na doutrina do direito constitucional o papel dos direitos fundamentais e das normas de princípio - mesmo daquelas consideradas meramente programáticas - como diretivas materiais permanentes, vinculando positivamente todos os ótgãos concretizadores, inclusive aqueles encarregados da jurisdição, devendo estes tomá-las em consideração em qualquer dos momentos da atividade concretrzadora ${ }^{13}$. Aliás, a mais importante fonte jurídica das normas de princípio são exatamente os direitos fundamentais.

\footnotetext{
${ }^{\prime C}$ C. a linha de desenvolvimento traçada com mão de mestre por Paulo Bonavides, Curso, cit., p. 526527, com mençăo ainda a diversos outros documentos relativos a direitos humanos produzidos no século XX.

12. Segue-se aqui a síntese realizada por Paulo Bonavides, Curso, cit., p. 516.524. O grande constitucionalista ainda menciona a quarta geração dos direitos fundamentais: o direito à democracia, o direito à informação e o direito ao pluralismo, direitos esses da maior importância, como se vế, mas que escapam aos limites estreitos deste estudo (ob. cit., p. 524-526).

13 J. J. Gomes Canotilho, Direito Constitucional, 4a. ed., Coimbra, Almedina, 1987, p. 132.
} 
Como se vê, cada vez mais nos distanciamos da concepção tradicional, que via os direitos fundamentais como simples garantias, como mero direito de defesa do cidadão em face do Estado e não, como os compreende a mais recente doutrina, como direitos constitutivos institucionais, com ampla e forte potencialização.

A questão revela-se particularmente sensivel porquanto dessa forma atribui-se ao órgão judicial, no plano jurídico-subjetivo, o poder de exercer positivamente os dircitos fundamentais (liberdade positiva) e de exigir omissões dos poderes públicos, de modo a evitar agressões lesivas por parre destes (liberdade negativa) ${ }^{14}$.

Por isso mesmo, em tal normatividade de caráter essencialmente principial encontrase contida autêntica outorga de competência para a livte investigação jurisdicional do direito. A particularidade aqui, em relação a outros tipos de regta juridicas, é que a competência para a descoberta mesma do direito no caso concreto vincula-se com os princípios de maneira ampla e indeterminada ${ }^{15}$. A constatação mostra-se deveras relevante, na medida em que, sendo facultado expressamente na Constituição o exercício de um direito produzido pelos juízes, legitima-se a atividade do Poder Judiciário perante a sociedade como um todo, mesmo diante da resistência de interesses contrariados.

4. Antes de analisar em espécie os direitos fundamentais que mais de perto dizem respeito ao processo - para depois procurar extrair algumas conseqüências práticas das premissas até agora estabelecidas - importa ter presentes ainda três aspectos essenciais implicados na sua concepção, a seguir enumerados:

a) A já mencionada normatividade do direito fundamental, notteadora não só da regulação legislativa do processo, como também do regramenro da conduta das partes e do órgão judicial no processo concreto e ainda na determinação do próprio conteúdo da decisão.

b) A supremacia do direito fundamental: "não são os direitos fundamentais que se movem no âmbito da lei, mas a lei que deve mover-se no âmbito dos direitos fundamentais" $"$

\footnotetext{
16. J. Gomes Canotilho, Direito Constitucional, cit., p. 448 .

is Assim, Issak Meier, Auflösung des geschriebenen Rechts durch allgemeine Prinzipiennormen, in Prinzipiennonmen und Verfahrensmaximem, em colaboraçāo com Rudolf Ottomann, Zürich, Schulthess Verlag, 1993, p. 56-58. Na mesma esteira, observa José Carlos Vieira de Andrade, Os direitos fundamentais na Constiruçăo portuguesa de 1976, Coimbra, Almedina, 1987, p. 256, que, na falta de lei que concretize determinado direito fundamental, "o princípio da aplicabilidade directa vale como indicador de exeqüibilidade imediata das nomas constitucionais, presumindo-se a sua perfeição, isto é, a sua autosuficiência baseada no caráter liquido e certo do seu conteúdo de sentido. Vão, pois, aqui incluidos o dever dos juízes e dos demais operadores juridicos de aplicarem os preceitos constitucionats e a autoxizaçăo para com esse fim os concretizarem por via interpretativa".

1* CF, a expressiva formulação de Jorge Mitanda, Manual, cit., no $60-1$, p. 282-283.
} 
c) O caráter principiológico do direito fundamental, a iluminar as regras já existentes, permitindo ao mesmo tempo a fotmulação de outras regras específicas para solucionar questôes processuais concretas.

Sob o último ângulo visual, o direito fundamental apresenta-se como norma aberta, a estabelecex pura e simplesmente um programa e afirmar certa direção finalística para a indispensável concretização jurisdicional, em oposição, assim, àquelas normas que contêm una ordem positiva ou negativa, capazes de serem apreendidas pelo juiz de forma mais ou menos direta ${ }^{17}$.

5. De passagem, é interessante observar que embora a oposição entre regras e princípios seja cada vez mais tênue, na medida em que toda intepretação de texto, segundo a moderna hermenêutica, exige em maior ou menor medida um "fazer produtivo", não se mostra correto afirmar que toda tegra jurídica, por sua vez, contém em determinados limites uma norma de princípio ${ }^{18}$, o que de certa forma eliminaria a diferença qualitativa entre ambas as categorias, preconizada por Esser.

A aplicação concreta do direito fundamental, de qualquer modo, não se distancia radicalmente do processo de aplicação do direito em geral. Este, cono tentei demonstrar em. outra oportunidade ${ }^{19}$, apresenta-se necessariamente como obra de acomodação do geral ao concreto, a requercr incessante trabalho de adaptação e até de criação, mesmo porque o legislador não é onipotente na previsão de todas e inumeráveis possibilidades oferecidas pela inesgotácl riqueza da vida.

Assim, o rigor do formalismo resulta temperado pelas necessidades da vida, agudizando-se o conflito entre o aspecto unívoco das características externas e a racionalização material, que deve levar a cabo o órgão judicial, entremeada de imperativos éticos, regras utilitárias e de conveniência ou postulados políticos, que tompem com a abstração e a generalidade. O juiz, por sua vez, não é uma máquina silogística, nem o processo, como fenômeno cultural, presta-se a soluções de matemática exatidão. Isso vale, é bom ressaltat, rão só para o equacionamento das questões fáticas e de direito, como também para a condução do processo e notadamente no recolhimento e valorização do material fático de interesse para a decisão.

Mesmo a regra jurídica clara e aparentemente unívoca pode ser transformada em certa medida, de acordo com as peculiaridades do caso concreto, por valorações e idéias do próprio juiz.

${ }^{17}$ Cf. Xsaak Meier, ob. cit., p. 14. Segundo Joseph Esser, Principios y Pensamientos Jurídicos Generales y Formas que Adoptan en el Derecho Privado, trad. de Eduardo Valentí Fiol, Barcelona, Bosch, 1961, p. 6370, as regras contêm ordens diretas; os principios, apenas critérios para a justificaçāo de uma ordem.

${ }^{18}$ Como sugere, Isaak Meier, ob. cit., p. 53-54.

"C. A. Alvaro de Oliveira, Do Fonmalismo no processo Civil, cit., p. 190191. 
Já Aristóteles havia constatado o fenômeno, quando tratou na sua Ética a Nicômano, momento clássico na história da epieikeia, das relações entre legalidade e eqüidade. Para o estagirita, "o eqüitativo, se bem é justo, não o é de acordo com a lei, mas como una correção da justiça legal. A causa disso é que toda lei é universal e há casos nos quais não é possível tratar as coisas con exatidão de um modo universal. Naqueles casos, pois, nos quais é necessário falar de um modo universal, sem ser possivel fazê-lo exatamente, a lei aceita o mais corrente, sem ignotar que há algum erro". A cqüidade se prestaria, assim, para eliminar a distância entre a abstração da norma e a concretude do caso julgado: "tal é a natureza do eqüitativo: uma correção da lei na medida em que sua universalidade a deixa incompleta" 20 .

Cuida-se, bem entendido, de aplicar a lei com eqüidade, atividade conatural ao próprio a to de julgar, e não de substituí-la pela eqüidade. E nessa aplicação da regra ou do princípio, do direito tout court, o sistema funciona como língua, isto é, como sistema de regtas de uso das palavras da linguagem juridica na qual se nomeiam os fatos a serem apreciados $c$ valorizados. Na verdade, os significados expressos na língua jurídica, empregada na aplicação operativa do direito, são tão ambíguos copináveis como as regras de uso da língua jurídica ditada pelas normas ${ }^{21}$. Daí a permanente necessidade de contextualizá-los, pela inserção no contorno específico fático da causa, para se extrair a decisão justa e adequada do caso concreto, especialmente com a ajuda dos princípios.

6. No concernente aos direitos fundamentais e aos princípios, a concretização realizase exclusivamente pelo juiz no caso trazido ao seu conhecimento. Vale dizer que o seu conteúdo só pode ser determinado diante de fatos específicos, considerando-se ainda que para essa aplicação são estabelecidos poucos limites, a não ser a coetência com os fundamentos constitucionais, o sistema jurídico $\mathrm{e}$ a linguagem interna do direito. Em contrapartida, o conteúdo da regra está previsto na própria regra, com maior ou menor precisão.

Dito isso, podem ser estabelecidas algumas linhas de aplicação das normas infraconstitucionais na perspectiva dos direitos fundamentais.

Assimn, em primeiro lugat, a interpretação deve ser conforme à Constituição, encarada esta de forma global, com ponderação de valores entre os direitos fundamentais adequados e o bem protegido pela lei restritiva. Vale dizer: 0 aplicador da norma deve inclinar-se pela interpretação que conduza à constitucionalidade da norma, embora por outra via pudesse considerá-la inconstitucional ${ }^{22}$.

20 Arrstóteles, Etica Nicomáquea, trad. esp. de J. Palli Bonet, Madrid, Gredos, 1985, V, 10, 1137b, p. 263.

${ }^{23}$ Cf. Luigi Ferrajoli, Derecho y Razón - Teoria del Garantismo Penal, trad. de Perfecto Andrés lbañez et al, prólogo de Norberto Bobbio, Madrid, Trotta, 1995, p. 56. Timbém a correlação entre a língua e a linguagem interna do sistema é essencial para a teoria hermenêutica preconizada por Tercio Sampaio Ferraz, Introdução ao Estudo do Direito - Técnica, Decisão, Domintaçâo, São Paulo, Atlas, 1989, p. 231-281, assentada no teor da traduçăo.

${ }^{22}$ A respeito, por todos, Paulo Bonavides, Curso, cit., p. 473-480. Com una visão sistemática da dortrina alemã e da jurisprudência do Tribunal Constitucional Federal alernão, Gilnar Ferreira Mendes, Jurisdição Constitucional -m O Controle Abstrato de Normas no Brasil e na Alemanha, 3a. ed., São Paulo, Saraiva, 1999, p. 231-237. 
Às vezes, mostra-se necessária até a correção da lei pelo órgão judicial, com vistas à salvaguarda do predomínio do valor do direito fundamental na espécie em julgamento. Já não se cuida, então, de mera interpretação "conforme à Constituição", mas de correção da própria lei, orientada pelas normas constitucionais e pela primazia de valor de determinados bens jutídicos dela deduzidos, mediante interpretação mais favorável aos direitos fundamentais. Significa isto que, havendo dúvida, deve prevalecer a interpretação que, conforme o caso, restrinja menos o direito fundamental, dê-lhe maior proteção, amplie mais o seu âmbito, satisfaça-o em maior grau ${ }^{23}$.

Ourro aspecto a ser sublinhado, com repercussão imediata na vida das pessoas, é a determinação do alcance dos direitos fundamentais e dos princípios que colidam entre si no caso em julgamento, da ponderação dos valores e da determinação do que deva prevalecer para a justiça do caso, consoante o chamado princípio da proporcionalidade, regra hoje inafastável de hermenêutica ${ }^{24}$. Aliás, além de conflitarem, os princípios podem também complementat-se ou delimirar-se entre $\mathrm{si}^{25}$.

Na conhecida visão de Alexy, a otimização por meio dos princípios dá-se em consonância com as possibilidades normativas e fáticas. Normativas, porque a aplicação dos princípios depende dos princípios e regras que a eles se contrapõem ou os complementam. Fáticas, porque o conteúdo dos princípios, para que se rransforme em norma concreta, só pode ser determinado pela concretude fática do caso ${ }^{26}$.

7. Do ponto de vista do direito processual, impõe-se sublinhar que os direitos fundarnentais, para poderem desempenhar sua função na realidade social, precisam não só de normatização intrinsecamente densificadora como também de formas de organização e

\footnotetext{
2.3 J. J. Gomes Canotitho e Vital Moreira, Fundamentos da Constituiçăo, Coimbra, Coimbra ed., 1991, ${ }^{\circ}$ 4.9, p. 143. Como bem ressalta Marcelo Lima Guexza, Execução Indireta, São Paulo, RT, 1998, p. 53, tratase de "adequar os resultados práticos ou concretos da decisão o máximo possível ao que dererminam os direitos fundamentais em jogo."

${ }^{24}$ Humberto Bergmann Avila, Distinção entre Princípios e Regras e a Redefinição do Dever de Proporcionalidade, Revista de Direito Administrativo, 215 (jan./mar.1999):151-179, esp. p. 170, demonstra de maneira adequada tratar-se, na realidade, de postulado nornativo-aplicativo, pois impõe uma condição formal estrutural de conhecimento concreto (aplicaçăo) de outras normas, condição essa de caráter normativo, institúía pelo própro direito para a sua devida aplicação, na busca de realizaçāo integral dos bens juxidicamente resguardados. Daí a defnição do dever de proporcionalidade como "um postulado normativo aplicativo decorrente da estrutura principial das normas e da atributividade do Direito, e dependente do conflito de bens juxídico materiais e do poder estruturador da relação meio-fim, cuja função é estabelecer uma medida entre bens jurídicos concretamente correlacionados" (p. 175).

${ }^{25}$ Ressalta acertadamente Karl Larenz, Metodologia da Ciência do Direito, trad. de José Lamego, 3a. ed., Lisboa, Gufbenkian, 1997, p. 483, que os direitos fundamentais e princípios nāo estão uns a par dos outros, sem conexão, mas que se relacionam uns com os outros de acordo con o sentido e, por isso, podem tanto complementat-se como delimitar-se entre si.

${ }_{25}$ Apud Humberto Bergmann Ávila, ob. cit., p. 159.
} 
tegulamentação procedimentais apropriadas. Daí a necessidade de estarem assegurados constitucionalmente por normas, principiais ou não, garantindo-se ao mesmo tempo seu exercício e restauração, em caso de violaçăo, por meio de órgãos imparciais com efetividade e eficácia ${ }^{27}$. Embora essa dimensão procedimental nem sempre se refira ao processo judicial, também o abrange, a evidenciar uma interdependência relacional entre direitos fundamentais eprocesso.

Faceta importante a ressaltar é que a participação no processo para a formação da decisão constitui, de forma imediata, uma posição subjetiva inerente aos direitos fundamentais, portanto é ela mesma o exercício de um direito fundamental ${ }^{28}$. Tal participação, além de constituir exercício de um direito fundamental, não se reveste apenas de caráter formal, mas deve ser qualificada substancialmente.

Isso me leva a extrair do próprio direito fundamental de participação a base constitucional para o princípio da colaboração, na medida em que tanto as partes quanto o órgão judicial, como igualmente todos aqueles que participam do processo (serventuários, peritos, assistentes técnicos, testemunhas etc.), devem nele intervir desde a sua instauração até o último ato, agindo e interagindo entre si com boa-fé e lealdade.

Para o Tribunal Constitucional espanhol, o dever judicial de promover e colaborar na realização da efetividade da tutela jurisdicional não é de caráter motal, mas um dever jurídico constitucional, pois os juizes e tribunais têm a "(...) obrigação de proteção eficaz do direito fundamental (...)". O cumprimento desse mandato constirucional de proteger o direito fundamental à tutela judicial efetiva, a que têm direito todas as pessoas, há de ser para os juizes e tribunais norre de sua atividade jurisdicional. Por isso, o Tribunal Constitucional fala da necessária colabotação dos órgãos judiciais com as partes na marerialização da turela e rambém no dever específico de garantir a tutela, dever que impede os órgãos jurisdicionais de adotarem uma atitude passiva nesta matéria ${ }^{29}$.

Por outro lado, a dependência crescente de previsão e de distribuição estatal e por conseqüência o perigo crescente de colisão entre os direiros de liberdade e as posições de direitos fundamentais, que estes ocupam no mundo atual, acaba por exercet influência

\footnotetext{
${ }^{27}$ Por isso, afixma Konrad Hesse, Elementos de Direito Constitucional da República Federal da Alemanha, trad. da 20a. ed. alemã por Luís Afonso Feck, Porto Alegre, Fabris, 1998, n 359, p. 288, que os dixeitos fundamentais requerem, em maior ou menor proporçāo, regulação da organização e do procedimento, e ao mesmo tempo influem sobre o direito de organização e procedimento, o que contribui para a sua própria realização e asseguramento.

${ }_{28}$ Assim, J. J. Gomes Canotilho, Tópicos de um Curso de Mestrado sobre Direitos Fundamentais, Procedimento, Processo e Organização, Boletim da Faculdade de Direito de Coimbra, 1990, p. 151-163, esp. p. 155, com amparo na sugestão do status activus processualis, formulada por P. Häberle.

20. Cf. Francisco Chamorro Bernal, La Tutela Judicial Efectiva (Derechos y garantias procesales derivados del articulo 24.1 de la Constitución), Barcelona, Bosch, 1994, p. 329, com menção a diversos precedentes (ob. cit., p. 329-330 e notas 72 a 77 ).
} 
decisiva no papel destinado ao direito processual. E isso porque os direitos fundamentais exibem acentuada força de irradiação sobre o direito legislado, a acentuar ainda mais o papel dos tribunais na "descoberta" do direito aplicável ao caso concreto.

À luz dessas considcrações, a participação no processo e pelo processo já não pode ser visualizada apenas como instrumento funcional de democratização ou realizadora do direito material e processual, mas como dimensão intrinsecamente complementadora e integradora dessas mesmas esfetas. O próptio processo passa, assim, a ser meio de formação do direito, seja material, seja processual. Tudo isso se potencializa, quando se atenta em que o processo deve servir para a produção de decisões conforme a lei, corretas a esse ângulo visual, tmas, além disso, dentro do marco dessa correção, presta-se essencialmente para a produção de decisões justas ${ }^{30}$.

8. Como fonte específica de normas jurídicas ptocessuais devem ser considerados especialmente dois grupos de direitos fundamentais, pertinentes aos valores da efetividade e da segurança jutídica ${ }^{33}$, valores esses instrumentais em relação ao fim último do processo, que é a realização da Justiça no caso concreto.

No primeiro grupo desponta fundamentalmente a garantia de acesso à jurisdição (art. $5^{\circ}$, inciso XXXV, da Constituição da República).

É claro que não basta apenas abrir a porta de entrada do Poder Judiciário, mas prestar jurisdição tanto quanto possivel eficiente, efetiva e justa, mediante um processo sem dilações ou formalismos excessivos.

Exatamente a perspectiva constitucional do processo veio a contribuir para afastar o processo do plano das construções conceituais e meramente técnicas e inseri-lo ná realidade política e social. 'Tal se mostra particularmente adequado no que diz respeito ao formalismo excessivo, pois sua solução exige o exame do conflito dialético entre duas exigências contrapostas, mas igualmente dignas de proteção, asseguradas constitucionalmente: de um lado, a aspiração de um rito munido de um sistema possivelmente amplo e articulado de garantias "formais" e, de outro, o desejo de dispor de um mecanismo processual eficiente e funcional.

Nessa linha de entendimento, a Corte Européia dos Direiros do Homem em vários pronunciannentos vem proclamando que a Convenção Européia dos Direitos do Homem ostenta por finalidade proreger direitos não mais "teóricos ou ilusórios, mas concretos e eferivos" 32 .

\footnotetext{
31) Assin, Robert Alexy, Teoria de los Derechos Fundamentales, cit., p. 472, endossando entendimento nesse sentido do Tribunal Constitucional Federal alemão. Sobre o ponto, C. A. Alvaro de Oliveira, Do Fomalismo, cit., p. 65-66. De observar que um dos valores supremos da ordem constitucional brasileira é a Justiça, como ressaltado no Preâmbulo da Constiuiçāo de 1988.

3 Aspecto sublinhado con grande acuidade por Teori Abino Zavascki, Antecipação de Tutela, São Paulo, Saraiva, 1997 , p. $64-65$.

${ }^{32}$ Arestos de 24.7.1968, no caso "lingǘstico belga", série A, n $\mathrm{n}^{\circ}$, p. $31, \$ \int 3$ in fine e 4; Golder vs. ReinoUnido, de 25.2.1975, série $A, n^{\circ} 18, \mathrm{p}, 18, \$ 35$ in fine; Luedicke, Belkacem e Koç, de 28.11.1978, série A, $\mathrm{r}^{\circ} 29$, p. 17-18, $\$ 41$; Marckx, de 136.1979, série $A, n^{\circ} 31$, p. 15, $\$ 31$, apud Bertrand Fravreau, Aux sources du procès équitable une certaine idée de la qualité de la Justice, in Le procès équitable ct la protection juridictionnelle du citoyen, Bruxelles, Bruylant, 2001, p. 11 e nota 3.
} 
Para a Corte, a efetividade supõe, além disso, que o acesso à justiça não seja obstaculizado pela complexidade ou custo do procedimento. Tal implica que as limitações, sempre deixadas à margem de apreciação dos Estados nacionais, não podem em nenhum caso restringir o acesso assegurado ao litigante de tal maneira que seu dircito a um tribunal seja atingido em sua própria substância, devendo ser observada "uma relação razoável de proporcionalidade entre os meios empregados e o fim visado". Ainda segundo o Tribunal, o litigante não deve ser impedido "de empregar un recurso existente e disponivel", proibindose todo "entrave desproporcional a seu direito de acesso ao tribunal" 33 .

Da mesma forma acentuou o Tribunal Constitucional espanhol que "(..) as normas que contêm os requisitos formais devem ser aplicadas tendo-se sempre presente o fim pretendido ao se estabelecer ditos requisitos, evitando qualquer excesso formalista que os convertevia em meros obstáculos processuais e em fonte de incerteza e imprevisibilidade para a sorte das pretensões em jogo" 34 .

Também o fator tempo veio a ganhar papel de destaque nesse quadro, ainda mais com a massificação das demandas levadas ao Judiciário e a conseqüente mudança de perfil dos usuários do sistema, a exigir uma solução mais ou menos premente do litígio. Daí a intensificação da tutela cautelar e antecipatória, da chamada jurisdição de urgência, em uma palavra, cujo substrato constitucional se mostra inegável. Também decorre desse imperativo a necessidade de se estabelecerem mecanismos de uma duração razoável do processo e, mais do que isso, da efetiva satisfação do direito reconhecido judicialmente, sen maiores delongas ${ }^{35}$.

Por outro lado, a própria noção de Estado Democrático de Direito, erigida a princípio fundamental da Constituição Brasileira (art. $1^{\circ}, c a p u t$ ), constitui substrato capital para a segurança jurídica, na medida em que salvaguarda a supremacia da Constituição e dos direitos fundamentais, garantind o cidadão contra o arbitrio estatal, assegurando ao mesmo tempo elementos fundantes imprescindíveis a qualquer sociedade realmente democrática, como o princípio democrático, o da justiça, o da igualdade, o da divisão de poderes e o da legalidade ${ }^{36}$.

\footnotetext{
${ }_{33}$ Arestos Levages Prestations Services vs. França, de 23.10.1996, Recueil, 1996-V, p. 1996.V, p. 1543, $\$ 40$, Brualla Gómez de la Torre vs. Agne, de 19.12.1997, \$33, Garcia Manibardo vs. Espanha, de 15.2.2000, apud, apud Bertrand Fravreau, ob. cit., p. 11 e nota 8.

${ }^{34}$ Sentença 57, de 8.5.1984, na linha de outros precedentes, como ressalta Francisco Chamorro Bernal, La Tutela, cit, p. 315. Adiante, ob. eit., p. 317, refere que o mesmo tribunal entendeu haver excesso de formalismo na inadmissão de recurso por faltar 360 pesetas num preparo de 327.846 .

35 Oportuna a recomendação de José Rogério Cruz e Tucci, Tempo e Processo, São Paulo, RT, 1997, p.146, passim, quanto à necessidade de serem adotados mecanisnos endoprocessuais de repressão à chicana, de aceleração do processo e de controle (urisdicional) externo da lentidão.

3 Sobre o ponto, José Afonso da Silva, Curso, cit., p. 103-108, e J. J. Gomes Canotilho c Vital Moreira, Fundamentos, cit., p. 82-85. Walther J. Habscheid, Droit Judiciaire Privé Suisse, Geneve, Librairie de L'Université, $1981, \$ 50, \mathrm{I}$, p. 306, tratando da autoridade da coisa julgada, menciona que o Tribunal Federal Constitucional alemão (BverfGE 15, 319) sublinhou que o Estado de Direito tem como tarefa preservar a segurança do dixeito.
} 
De mais a mais, o desenvolvimento, que se pode julgat excessivo, da penalização da vida social e política exige sejam as regras juridicas formuladas de maneira simples, clara, acessível e previsível: daí a noção de Estado de Direito e o princípio da segurança jurídica, produtos de desenvolvimentos sociais cada vez mais complexos e de evoluçôes cada vez mais incertas ${ }^{37}$.

Em tal contexto, ganha lugar de destaque o devido processo legal ${ }^{38}$ (art. $5^{\circ}$, inciso LIV, da Constituição da República), princípio que exige como corolários a proibição de juízos de exceção e o princípio do juiz natural (art. $5^{\circ}$, incisos XXXVII e LIII), a igualdade (art. $5^{\circ}$, caput), aí compreendida a paridade de armas ${ }^{34}$, o contraditório e a ampla defesa, com os meios e tecursos a ela inerentes (art. $5^{\circ}$, inciso LV), consideradas inadmissíveis as provas obtidas por meios ilícitos (art. $5^{\circ}$, inciso LVI), devendo o litígio ser solucionado por meio de decisão fundamentada (art. 94, inciso IX).

9. À vista do exposto, pode-se concluir que garantismo e e ficiência devem ser postos em relação de adequada proporcionalidade, por meio de uma delicada escolha dos fins a atingir e de uma atenta valoração dos interesses a tutelar. E o que interessa tealmente é que nessa dificil obra de ponderação sejam os problemas da justiça solucionados num plano diverso e mais alto do gue o puramente formal dos procedimentos e transferidos ao plano concernente ao interesse humano objeto dos procedimentos: um processo assim na medida do homem, posto realmente ao serviço daqueles que pedem justiça ${ }^{40}$.

Em suma, com a ponderação desses dois valores fundamentais - efetividade e segurança jurídica - visa-se idealmente a alcançar um processo tendencialmente justo.

Observe-se, finalmente, à vista do caráter essencialmente principiológico dos direitos fundamentais, que só se pode determinar o que se entende por processo justo levando-se en conta as circunstâncias peculiares do caso.

${ }^{34}$ Cf. Bertrand Mathieu e Michel Verpeaux, Contentieux Constitutionnel des Droits Fondamentaux, Paris, LGDJ, 2002, p. 703, que ressaltam o emprego substancial desses conceitos tanto pelo juiz constitucional francês quanto pelo juiz ordinário.

${ }^{38}$ Cezar Saldanha de Souza Júnior, en suas aulas na Faculdade de Direito da Universidade Federal do Rio Grande do Sul, tern criticado essa forma de expressar a cláusula do due process of law, ao argumento de que law também é direito, propondo seja adotada a fótmula "devido processo de direito". A sugestão certamente é adequada à função do princípio. Todavia, alérn de a expressão estar consagrada pelo uso, não me parece esteja equivocada a tradução, em vista de que, no seu primeiro emprego no Estatuto do Rei Eduardo III (1354), como informa Kenneth Pennington, The Prince and the Law, 1200-1600 (Sovereignty and Rights in the Western Legal Tradition), Berkeley, University of California Press, 1993, p. 145, nota 95, fazia-se referência expressa à lei: "saunz estre mesne en repons par due proces de lei".

39 Para a Corte Européia dos Direitos do Homem, "consoante o princípio da igualdade de armas — um dos elementos da noção más ampla de processo eqüitacivo -, deve ser oferecida a cada una das partes a possibilidade razoável de apresentar sua causa em condições tais que não a coloquem em situação de desvantagem em relação à outra": Assim, v.g, arestos Dombo Beheer B.V vs Países-Baixos, de 27.10.1993, série A, $\mathfrak{t}^{\circ} 274, \$ 33$, Bulut v. Austria, de 22.2.1996, Recuell 1996, II, $₫ 47$, Foucher vs. França, de 17.3.1997, $\$ 34$, Kuopila vs. Firtlândia, de 27.4.2000, apud Silvio Marcus.Helmons, Quelques aspects de la nocion d'égalité des armes (Un aperçu de la jurisprudence de la Cour européenne des droits de l'homme), in Le procès équitable, cit., p. 68.

to Detecta o problema, insere-o na perspectiva constitucional e o resolve nos termos enunciados no texto Nicolò Trocker, Processo Civile e Costuturione - Problemi di Dirito Tedesco e Italiano, Milano, Giuffrè, 1974, p 734-736. 